\title{
Multiple primary synchronous malignant tumors
}

\author{
Alberto Testori ${ }^{1}$, Ugo Cioffi ${ }^{*}$, Matilde De Simone ${ }^{2}$, Francesco Bini ${ }^{3}$, Adriano Vaghi ${ }^{3}$, Alessandro A. Lemos ${ }^{4}$, \\ Michele M. Ciulla ${ }^{5,6}$ and Marco Alloisio ${ }^{1}$
}

\begin{abstract}
Background: Patients with primary multiple malignancies are progressively increasing due to prolonged survival of cancer patients and to the advances in diagnostic techniques and therapeutic options.

Case presentation: Here we present a 66 year-old caucasian patient with four synchronous primary malignant tumors affecting the lung, oropharynx, large bowel and prostate gland, respectively, treated with multidisciplinary approach.

Conclusions: The increased incidence of multiple malignant tumors is a real challenge to the clinician and clinical attention should be made to avoid a misdiagnosis. In addition an early diagnosis is essential to achieve a radical treatment. We believe that the treatment modality should be carefully made and tailored on the individual patient suffering from this disease.
\end{abstract}

Keywords: Multiple primary malignancies, Synchronous tumors, Metachronous tumors

\section{Background}

Patients with multiple primary malignancies (MPMs) are progressively increasing; these tumors may be metachronous or synchronous. This distinction implies important diagnostic and therapeutic challenges. From a diagnostic point of view the different patterns of MPMs should be considered. Therapeutically, a multi-disciplinary and patient-oriented approach should be considered. Hereby, we present a case of four primary malignant synchronous tumors affecting the lung, oropharynx, large bowel and prostate gland, respectively.

\section{Case presentation}

A 66-year-old male was referred to our department because of cough, chest pain and weight loss. His past clinical history, family history were unremarkable. Given the persistency of symptoms, chest X-ray was performed and showed a subtle opacity at the upper segment of the right lower lung. Whole body computed tomography (CT) scan confirmed the presence of a pulmonary

\footnotetext{
*Correspondence: ugo.cioffi@guest.unimi.it

${ }^{2}$ Depatment of Surgery, University of Milan, Milan, Italy

Full list of author information is available at the end of the article
}

malignant-looking nodule without hilar lymphadenopathy. ${ }^{18} \mathrm{~F}$-fluorodeoxyglucose positron emission tomography (FDG-PET) revealed avid uptake of the pulmonary nodule as well as oropharyngeal, sigmoid colon, and prostate gland uptake (Fig. 1). Subsequently, the patient underwent video-assisted bronchoscopy, which revealed normal findings. Conversely, video-assisted laryngoscopy showed an infiltrative ulcerated lesion involving the base and both valves of the tongue. Oropharyngeal biopsy was performed and histology revealed an infiltrative squamous cell carcinoma. Subsequently, CT guided lung biopsy showed a lung adenocarcinoma. The patient underwent colonoscopy with polypectomy and histology revealed the presence of adenocarcinoma. Finally, specimen from the prostate gland revealed an adenocarcinoma (Gleason score: $3+3$ ), too (Table 1). Abnormally enlarged lymph nodes in the abdomen up to $1.7 \mathrm{~cm}$ in diameter along with several non-specific lymph nodes have been identified. CT scan of the neck and facial bones showed a bulky mass in the right aspect of the oral cavity, infiltrating the base of the tongue with preservation of the adjacent mandibular cortical bone abutting the midline, given a horseshoe-like appearance of 


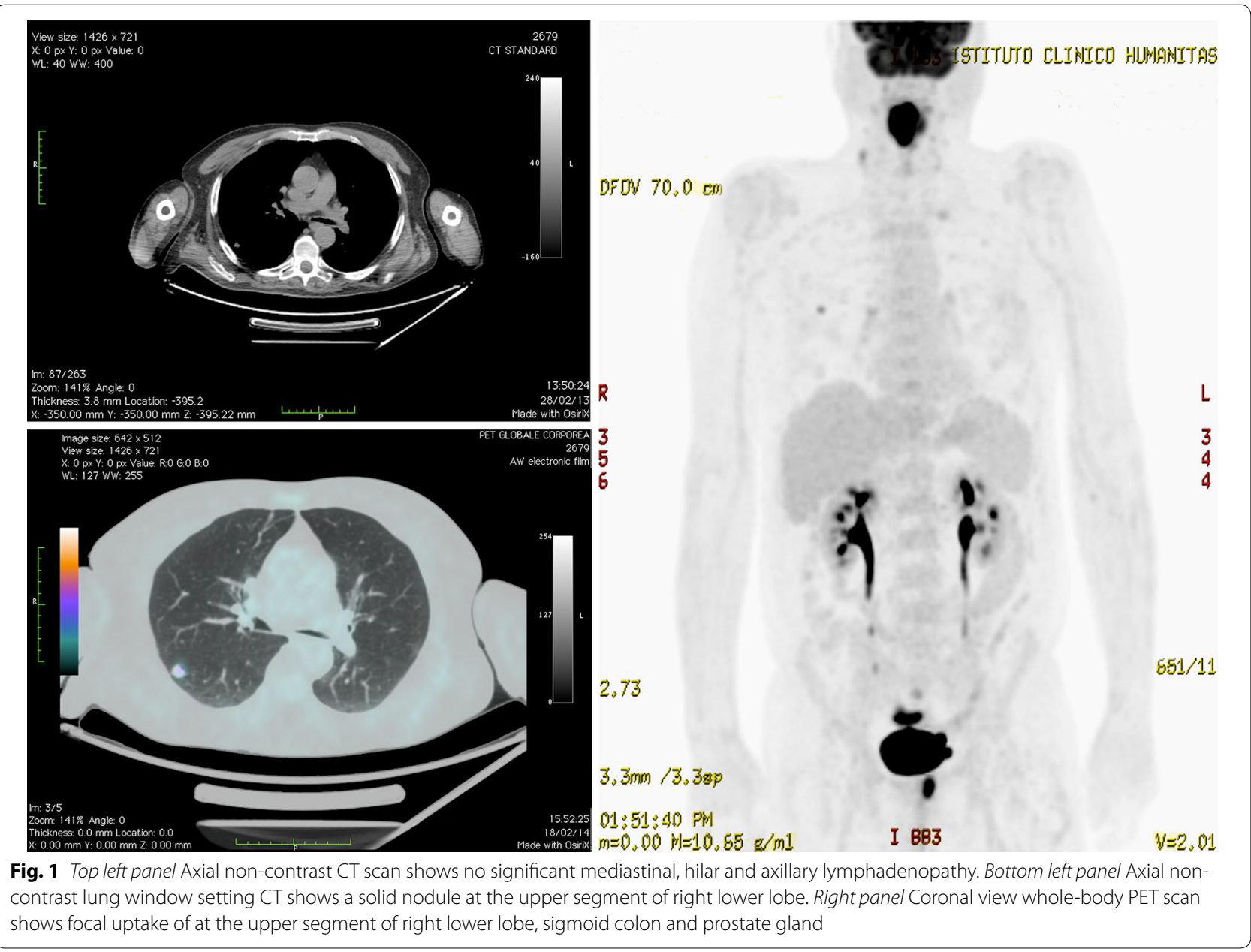

Table 1 Clinical history of the patient: diagnosis and treatment

\begin{tabular}{|c|c|c|c|c|}
\hline Date (mm/dd/yrs) & Examination & Histology & Date $(\mathrm{mm} / \mathrm{dd} / \mathrm{yrs})$ & Treatment \\
\hline 02/08/2013 & Laringoscopy biopsy & $\begin{array}{l}\text { Vegetating lesion base of the } \\
\text { tongue } \\
\text { Infiltrating and ulcerating squa- } \\
\text { mous cell carcinoma C2-C3 }\end{array}$ & $\begin{array}{l}\text { From } 03 / 12 / 2013 \text { to } \\
\text { 04/13/2013 }\end{array}$ & $\begin{array}{l}2 \text { cycles of TPF (taxotere/ } \\
\text { cisplatin/5-fluoruracil) plus } \\
\text { rasdiation therapy on nodes } \\
\text { PET + and loco regional } \\
(69.96 \mathrm{~Gy}) \text { and on orofarinx } \\
(54.45 \mathrm{~Gy})\end{array}$ \\
\hline 02/08/2013 & CT-guided pulmonary biopsy & $\begin{array}{l}\text { Subpleural lesion of the right } \\
\text { upper lobe } \\
\text { Pulmonary Adenocarcinoma } \\
\text { TTF1(+) e CDX2(-).pT1a No }\end{array}$ & $09 / 30 / 2013$ & $\begin{array}{l}\text { Right lower lobectomy } \\
\text { No chemotherapy }\end{array}$ \\
\hline $02 / 13 / 2013$ & $\begin{array}{l}\text { Pancolonscopy } \\
\text { Polipectomy }\end{array}$ & $\begin{array}{l}\text { Adenocarcinoma CDX2(+); } \\
\text { TTF1 }(-) \text {.pT3a N2b RO }\end{array}$ & $07 / 11 / 2013$ & $\begin{array}{l}\text { Left hemicolectomy } \\
\text { Adjuvant chemotherapy }\end{array}$ \\
\hline 03/07/2013 & Prostatic biopsy & $\begin{array}{l}\text { Adenocarcinoma Grading Glea- } \\
\text { son score } 4+3 ; p T 3, N 2 b, R O B\end{array}$ & 07/11/2013 & $\begin{array}{l}\text { Prostatectomy } \\
\text { No chemotherapy }\end{array}$ \\
\hline
\end{tabular}

the tumor. There was infiltration of the muscles of the tongue base whereas the left mylohyoid muscle was preserved. Bilateral enlarged lymph nodes at level II and III have been identified. Given the presence of these multiple malignant tumors, multidisciplinary assessment was necessary. The laryngeal lesion was treated by radio and chemotherapy whereas the sigmoid and prostate tumors were treated by surgical excision. In regard to the 
pulmonary tumor, the decision about whether surgery or radiotherapy would be more appropriate was considered later. Consequently, chemotherapy and radiotherapy were started given almost complete resolution of the lung tumor; instead we observed progression of the sigmoid tumor along with two enlarged lymph nodes in the pelvis, whereas the tumor of the prostate gland did not change in size. The patient had left hemicolectomy and prostatectomy, which confirmed the presence of adenocarcinoma with features of vascular invasion, adipose tissue invasion, and no extramural or perineural involvement. Metastases were found in 10 out of 19 lymph nodes. As a result, the histological staging was pT3 N2B R0 B. Prostatic specimen confirmed the presence of adenocarcinoma with no infiltration of the urinary bladder. However, multifocal extension by the tumor to the adjacent tissues was observed. A 30-day interval follow-up PETCT scan showed an avid focal uptake at segment 5 of the liver suspicious of a sigmoid adenocarcinoma metastasis and at the apical segment of the right lower lobe in accordance with the known pulmonary tumor. A further multidisciplinary assessment regarding the appropriate patient's management suggests surgical treatment for the pulmonary lesion, stereotactic radiotherapy for the metastatic deposit in the liver and adjuvant chemotherapy for the sigmoid tumor of colon. Surgical specimen after right lower lobectomy showed a G3 type lung carcinoma with prevalent aspects of acinar growth and absence of pleural infiltration, vascular invasion, or necrosis. The tumor did not involve the bronchial or vascular surgical resection margins or adjacent lymph nodes. Immunocytochemistry was TTF1 $(+)$ and CDX2 (-), whereas histopathological staging was pT1 N0. The patient received stereotactic radiotherapy for the liver metastasis and adjuvant chemotherapy for the sigmoid colonic tumor. An 18-month interval follow-up PET-CT scan demonstrated no recurrence.

\section{Conclusions}

Since the first report of Billroth and the definition of Warren and Gates [1], the incidence of multiple cancers had progressively increased over time. The first point that deserves clarification regarding multiple tumors is what does the term "primary" means. First, tumors must be histologically different. Second, they must involve different organs. Finally, metastatic lesions among these tumors must be excluded. MPMs are generally divided into 2 categories: metachronous, when tumors follow one another regardless a fixed period of time and synchronous, when tumors arise simultaneously or within 6 months from the primary malignant tumor [2]. Metachronous are more frequent than synchronous tumors with a ratio of 2.7: 1 . Second primary tumors are most common, whereas third and fourth primary tumors are relatively rare [3]. There are several explanations for the origin of these tumors. One is the growing incidence of multiple tumors due to increased lifetime [4]. Another is that effective anti-neoplastic therapy has led to a significant improvement in patients' survival from cancer. Therefore, survivors have a $20 \%$ higher risk of new primary cancer in the same or different organs than the general population [5]. The tendency of some subjects to develop multiple tumors (synchronous or metachronous) may be explained either by an individual predisposition or by the action of carcinogenic factors acting on different organs at different times. This is probable the explanation regarding the association between low growing and aggressive tumors, as reported in our case. The pathogenesis of multiple and single tumors has similar mechanisms. The combined action of environment and genetic factors facilitates the onset of a new tumor. Therefore, multifactorial and predisposing factors are likely responsible for the development of metachronous tumors [3]. Conversely, it is difficult to explain the origin of synchronous tumors, even if multifactorial and predisposing factor cannot be exclude, their onset seems to be more time depending. Even if there are several limitations in the current literature because most are case-report studies, the reported incidence of metachronous and synchronous tumors is relatively high [3]. Therefore, radiologists and clinicians should be aware about different patterns and clinical presentation of multiple malignant tumors. In conclusion, successful patient's management and increased life expectancy can be achieved by multidisciplinary management and patient-oriented approach in multiple primary malignant synchronous tumors.

\section{Consent}

Written informed consent was obtained from the patient for publication of this case report and accompanying images.

\section{Abbreviations}

MPMs: multiple primary malignancies; CT: computed tomography; FDG-PET: ${ }^{18} \mathrm{~F}$-fluorodeoxyglucose positron emission tomography; PET-CT: positron emission tomography-computed tomography; TTF1: thyroid transcription factor-1; CDX2: caudal type homeobox transcription factor-2.

\section{Authors' contributions}

AT, UC, MdS, FB, AV, AAL, MMC, MA have made substantial contributions to conception and design, or acquisition of data, or analysis and interpretation of data, have been involved in drafting the manuscript or revising it critically for important intellectual content and have given final approval of the version to be published. We state that there has been no duplicate publication or submission elsewhere, all authors have read and approved the manuscript, subject to acceptance, authors will transfer copyright to the Publisher, and there is no ethical problem or conflict of interest. All authors read and approved the final manuscript. 


\section{Author details}

1 Department of General and Thoracic Surgery, Humanitas Research Hospital, via Manzoni 56 Rozzano, 20089 Milan, Italy. ${ }^{2}$ Depatment of Surgery, University of Milan, Milan, Italy. ${ }^{3}$ Department of Pneumology, "G. Salvini" Hospital, Garbagnate Milanese, Milan, Italy. ${ }^{4}$ Department of Diagnostic Radiology, Princess Elisabeth Hospital, Channel Islands GY4-6UU, UK. ${ }^{5}$ Laboratory of Clinical Informatics and Cardiovascular Imaging, Department of Clinical Sciences and Community Health, University of Milan, Milan, Italy. ${ }^{6}$ Cardiovascular Diseases Fondazione IRCCS Cà Granda Ospedale Maggiore Policlinico, Milan, Italy.

\section{Acknowledgements}

We thank Dr. Gerardo Cioffi, native speaker, for reviewing the English language. The authors have not received funding for this case report.

\section{Competing interests}

The authors declare that they have no competing interests.

Received: 9 April 2015 Accepted: 20 November 2015

Published online: 27 November 2015

\section{References}

1. Warren $\mathrm{S}$, Gates O. Multiple primary malignant tumors: a survey of the literature and statistical study. Am J Cancer. 1932;16:1358-414.

2. Sakellakis M, Peroukides S, Iconomou G, Boumpoucheropoulos S, Kalofonos H. Multiple primary malignancies: report of two cases. Chin J Cancer Res. 2014;26:215-8.

3. $\mathrm{Xu} \mathrm{LL}$, and Gu KS. Clinical retrospective analysis of cases with multiple primary malignant neoplasms. Gen Mol Res 2014.

4. Yancik R, Ries LA. Aging and cancer in America. Demographic and epidemiologic perspectives. Hematol Oncol Clin North Am. 2000;14:17-23.

5. Luciani A, Balducci L. Multiple primary malignancies. Semin Oncol. 2004;31:264-73.

\section{Submit your next manuscript to BioMed Central} and we will help you at every step:

- We accept pre-submission inquiries

- Our selector tool helps you to find the most relevant journal

- We provide round the clock customer support

- Convenient online submission

- Thorough peer review

- Inclusion in PubMed and all major indexing services

- Maximum visibility for your research

Submit your manuscript at www.biomedcentral.com/submit
BioMed Central 